DOI: 10.17707/AgricultForest.65.4.01

\author{
Uwe BUCZKO*, \\ Kristin STEINFURTH, Michael VAN LAAK ${ }^{1}$
}

\title{
META-ANALYSIS OF THE YIELD RESPONSE TO PHOSPHORUS FERTILIZATION BASED ON LONG-TERM FIELD EXPERIMENTS
}

\section{SUMMARY}

Phosphorus (P) fertilizer recommendations in Germany and most other European countries are based on plant-available soil $\mathrm{P}$ contents and results from long-term field experiments. Site-specific conditions are often neglected, and consequently excessive $\mathrm{P}$ fertilizer rates have often been applied in the past decades. In this study, long-term field $\mathrm{P}$ fertilization experiments including relevant site and soil parameters were evaluated in order to analyze the yield response. The database comprises about 2000 datasets from 30 field experiments from Germany and Austria. Statistical evaluations using a classification and regression tree approach, and multiple linear regression analysis indicate that besides plant-available soil $\mathrm{P}$ content, soil texture and soil organic matter content have a large influence on the effectiveness of $\mathrm{P}$ fertilization. This study methodology can be a basis for modification and specification of existing $\mathrm{P}$ fertilization recommendations and thus contribute to mitigate environmental impacts of P fertilization.

Keywords: CART, Crop yield, Fertilization, Phosphorus, Plant-available soil phosphorus.

\section{INTRODUCTION}

In most countries, $\mathrm{P}$ fertilizer recommendations are based on the expected nutrient uptake by crops and the plant-available $\mathrm{P}$ content in the soil (JordanMeille et al., 2012), and the procedure entails three steps: (i) Extraction of plantavailable soil P, (ii) calibration of those soil test results, (iii) deducing recommended $\mathrm{P}$ fertilizer amounts.

In the calibration step, plant-available $\mathrm{P}$ contents are categorized into several classes (in Germany and many other countries five classes), which are interpreted in terms of nutrient supply and crop yields. These calibrations are mostly based on long-term fertilization trials (Kuchenbuch and Buczko, 2011; Buczko et al., 2018). However, the data base used for the calibration step is mostly not accessible in the international literature, and even in countries which

\footnotetext{
${ }^{1}$ Uwe Buczko*(corresponding author: uwe.buczko@uni-rostock.de), Kristin Steinfurth, Landscape Ecology and Site Evaluation, Faculty of Agriculture and Environmental Science, University of Rostock, Rostock, GERMANY; Michael Van Laak, State Office for Planning Permission, Ministry of Economic Affairs, Technology and Transport Schleswig-Holstein, Kiel, GERMANY

Paper presented at the $10^{\text {th }}$ International Scientific Agricultural Symposium "AGROSYM 2019".

Notes: The authors declare that they have no conflicts of interest. Authorship Form signed online.
} 
use the same extraction procedure, the boundaries of the nutrient availability classes may diverge considerably (Jordan-Meille et al., 2012). Various studies have shown that $\mathrm{P}$ fertilization recommendations in Germany and several other European countries have been too high in the past (Ott and Rechberger, 2012; Tóth et al., 2014; Withers et al., 2014), and consequently, the boundaries of the $\mathrm{P}$ fertility classes have been too high (VDLUFA, 2015). Moreover, besides plantavailable soil $\mathrm{P}$ contents, other factors have an influence on crop yields, for instance $\mathrm{pH}$ value, soil organic carbon content, clay content, weather and climate parameters. Although in Germany and other countries there is a large number of long-term field experiments dealing with the effects of $\mathrm{P}$ fertilization on crop yields (e.g., Baier et al., 2001; Spiegel et al., 2001; Merbach and Schulz, 2012), the results of those field fertilization trials have mostly not been compiled nor evaluated and analyzed as a whole in form of a meta-study. The objectives of this work were to compile a large database of long-term $\mathrm{P}$ fertilization experiments from Germany and Austria with special emphasis on data which have until now not been published. A meta-analysis of this data was conducted including statistical methods to evaluate the influence of various site-specific soil and environmental factors on the effectiveness of $\mathrm{P}$ fertilization.

\section{MATERIAL AND METHODS}

Data of 30 phosphorus fertilization trials across Germany and Austria were compiled (Buczko et al., 2018). All field experiments focused on the effect of P fertilization on yields and are therefore one-factorial fertilization trials with application rates ranging between 10 and $210 \mathrm{~kg} \mathrm{P} \mathrm{ha}^{-1} \mathrm{y}^{-1}$, i.e., 30 to $2000 \%$ of $\mathrm{P}$ export by crops. The final data base comprised well over 2000 data sets. Effects of fertilizer application rates on yields were compared by calculating the relative yield increases (YI in \%) from the ratio of the yield of the fertilized treatment $\left(\mathrm{y}_{\mathrm{f}}\right)$ and that of the zero fertilization (control) treatment $\left(\mathrm{y}_{0}\right)$ :

$$
\mathrm{YI}=\left(\left(\mathrm{y}_{\mathrm{f}} / \mathrm{y}_{0}\right)-1\right) * 100
$$

i.e., $\mathrm{YI}$ is the percentage value of the increase in crop yield of the fertilized treatment compared with the corresponding control treatment.

The studied soils have rather high soil P contents. Nevertheless, P fertilizer application rates are very high: in $50 \%$ of the data, more than $158 \%$ of the $\mathrm{P}$ was exported by harvested crops.

The fertilization trials have mostly been conducted over many years, and the duration of the experiments utilized in the present meta-analysis is in some cases longer than 20 years. The most frequent soil types were Luvisols. The crop rotations are dominated by the crops grown most commonly in Germany, i.e. winter wheat $(n=568)$, winter barley $(n=305)$, summer barley $(n=202)$, sugar beet $(n=200)$, potato $(n=197)$, and oilseed rape (canola) $(n=129)$.

The data of the field trials were analyzed with a classification and regression tree (CART) approach and multiple regression analysis. The CART methodology is based on splitting the data set into segments with a distinct factor 
combination. The impact of several predictor variables on a dependent variable is analyzed by successive binary splits. The resulting trees are easy to interpret, since the successive binary splits indicate the relative importance of the predictor variables in explaining the dependent variable. In addition, multiple linear regression analyses were conducted for comparison. Both the CART and regression analyses were done using the program SPSS (version 20.0).For both the CART and regression analyses, the dependent variable was the relative yield increase (YI), and the influencing factors (predictor variables) were plantavailable soil P content (soil test phosphorus, STP), clay content, organic carbon content, $\mathrm{pH}$ value, relative $\mathrm{P}$ fertilizer application rate, and crop species.

\section{RESULTS AND DISCUSSION}

The relation between STP and YI for all data points (Fig. 1) reveals highest YI for the soil P content class B and lower YI for higher P content classes. For all soil P classes, the large number of data points with negative YI, i.e., yield depressions, is striking. This is a phenomenon commonly observed in long-term fertilization trials (e.g., Jungk et al., 1993; Kuchenbuch and Buczko, 2011). The yield depressions are observed here more or less equally for all soil $P$ content classes (A: $20 \%$, B: $30.6 \%$, C: $29 \%$, D; 30.5\%, E: 41\% of datasets). High levels of plant available $\mathrm{P}$ (as provided by mineral fertilizer) in general reduce root density (Forde and Lorenzo, 2001), and development of mycorrhiza (Williams et al., 2017). This could have a negative impact on the uptake of water and other nutrient elements, for instance the micronutrients $\mathrm{Zn}$ and $\mathrm{Cu}$, thus reducing the yield of fertilized treatments.

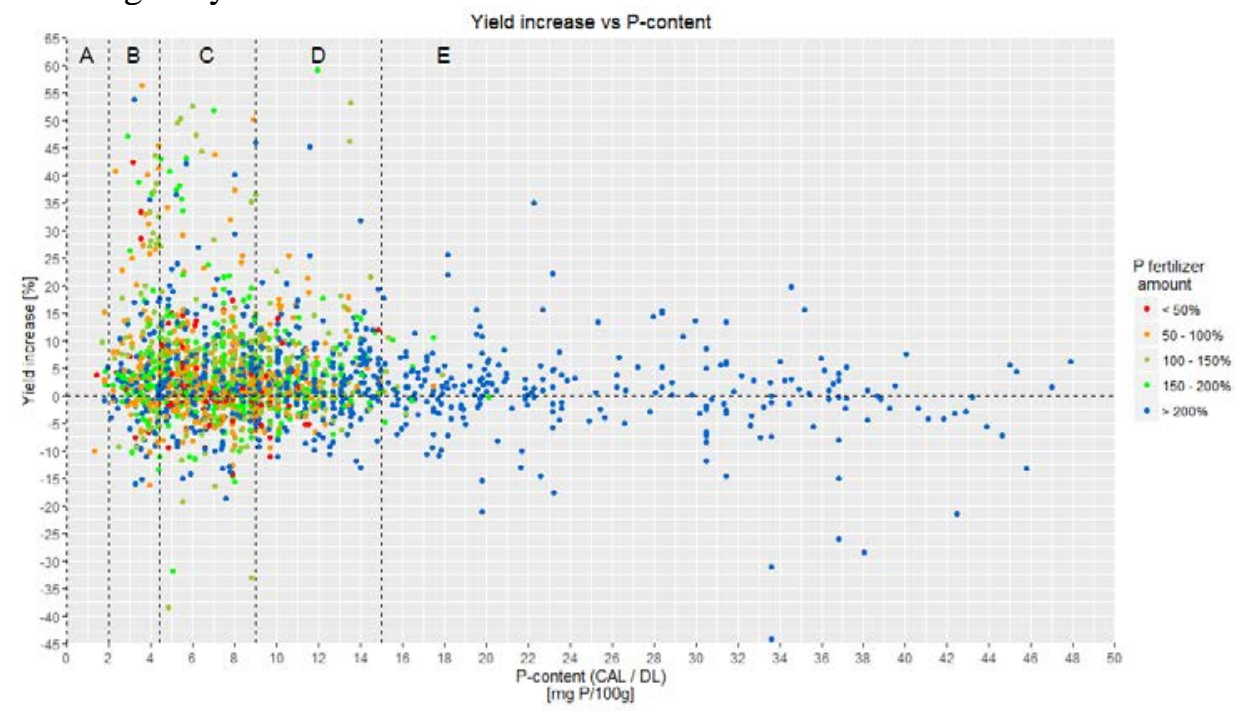

Figure 1. Rel. yield increase (YI) vs soil P content (CAL or DL); fertilizer application rate ("fertilizer amount") expressed as \% of P export by harvested crop; P-content classes according to VDLUFA (1997). 
Relative yield increases by $\mathrm{P}$ fertilization as a function of soil $\mathrm{pH}$ class show highest YI values for $\mathrm{pH}$ classes $\mathrm{A}$ and $\mathrm{B}$ (i.e., acid conditions with low $\mathrm{pH}$ values, $<6$ ), and lowest values for class $\mathrm{E}$ (high $\mathrm{pH}$ values, >7). This is probably connected with the direct correlation between STP and $\mathrm{pH}$ values (Pearson $\mathrm{r}=$ 0.41). At low $\mathrm{pH}$ values (<5.5), $\mathrm{P}$ is strongly adsorbed (e.g., by $\mathrm{Fe}-$ and $\mathrm{Al}-$ Oxides) in soils and therefore less readily plant-available. Additionally, soil $\mathrm{pH}$ influences the availability of other essential plant nutrients and soil microorganisms and might therefore cause yield effects not investigated in the evaluated phosphorus experiments. YI increases with SOM content, and highest YI values are observed for SOM contents of $2.5-3 \%$. However, for SOM $>3 \%$, $\mathrm{YI}$ is again significantly lower (but the number of data in that group is lower than in the other groups). In general, P availability is directly correlated with SOM contents, because adsorption of $\mathrm{P}$ is reduced by organic anions such as citrate or malate which compete with phosphate anions for adsorption sites at $\mathrm{Fe}$ and $\mathrm{Al}$ oxide surfaces (e.g., Gerke, 2015). This may explain the higher effect of P fertilization with higher SOM contents observed for our data. The relation between $\mathrm{P}$ fertilization rate and YI is evaluated here in terms of relative rates, i.e., $\mathrm{P}$ input divided by the $\mathrm{P}$ export by the harvested crop. Although the YI values are on average highest for relative rates of 100-150\%, the differences among the groups are mostly not significant, and conspicuously, the YI values are relatively low for high rates of P input (> $200 \%$ of exported P). Such a lack of stringent relation between $\mathrm{P}$ fertilizer amount and yield increase has been reported in previous studies (e.g., Jungk et al., 1993) and suggests that in most cases the pool of plant available $\mathrm{P}$ in the soil is sufficient for high crop yields, and the applied fertilizer $\mathrm{P}$ is used mainly to maintain or even enhance this soil $\mathrm{P}$ pool. This is in accordance with the philosophy of "maintenance fertilization" (Jordan-Meille et al., 2012), although recently this approach has been questioned (Withers et al., 2014). Additionally, more important than the applied amount of fertilizer is the $P$ content of the control plot. In cases where the soil $\mathrm{P}$ content of the unfertilized control is above $9 \mathrm{mg} \mathrm{P} / 100 \mathrm{~g}$, the fertilized plots only show an average yield increase of $1.1 \%$, irrespective of the total available P (soil P + fertilizer P) in the treatment plot.

When evaluating the effect of P fertilizer type on YI, there are statistically significant differences between treatments fertilized with Superphosphate and Thomasphosphate on one hand, and Triplesuperphosphate and Hyperphosphate on the other hand. The lower effectiveness of Hyperphosphate (i.e., finely ground rock phosphate) in non-acid soils compared with Superphosphate is expected and in line with previous studies (e.g., Spiegel et al., 2001; von Tucher, 2013). However, one would expect that Superphosphate and Triplesuperphosphate are similarly available, since both are produced by reaction of rock phosphate with inorganic acids (sulfuric acid and phosphoric acid). In contrast to Triplesuperphosphate, Superphosphate contains remnants of sulfate, which is a macronutrient. This could be an explanation for the higher effectiveness of Superphosphate. The relatively high effectiveness of Thomasphosphate could 
possibly be caused by the high content of $\mathrm{Ca}$ and micronutrients (e.g., $\mathrm{Fe}, \mathrm{Mn}$, $\mathrm{Zn}$ ), and the alkaline soil reaction induced by this fertilizer.

A comparison of the effectiveness of $\mathrm{P}$ fertilization among the six most common crops shows overall highest yield increase for summer barley, and lowest increases for winter wheat.

All the influencing factors mentioned above are considered in the CART and multiple regression analyses as independent variables. The first split in the CART analysis was set for the independent variable plant-available soil P content (STP) at a value of $3.34 \mathrm{mg} \mathrm{P} 100 \mathrm{~g}^{-1}$ soil (Fig. 2).

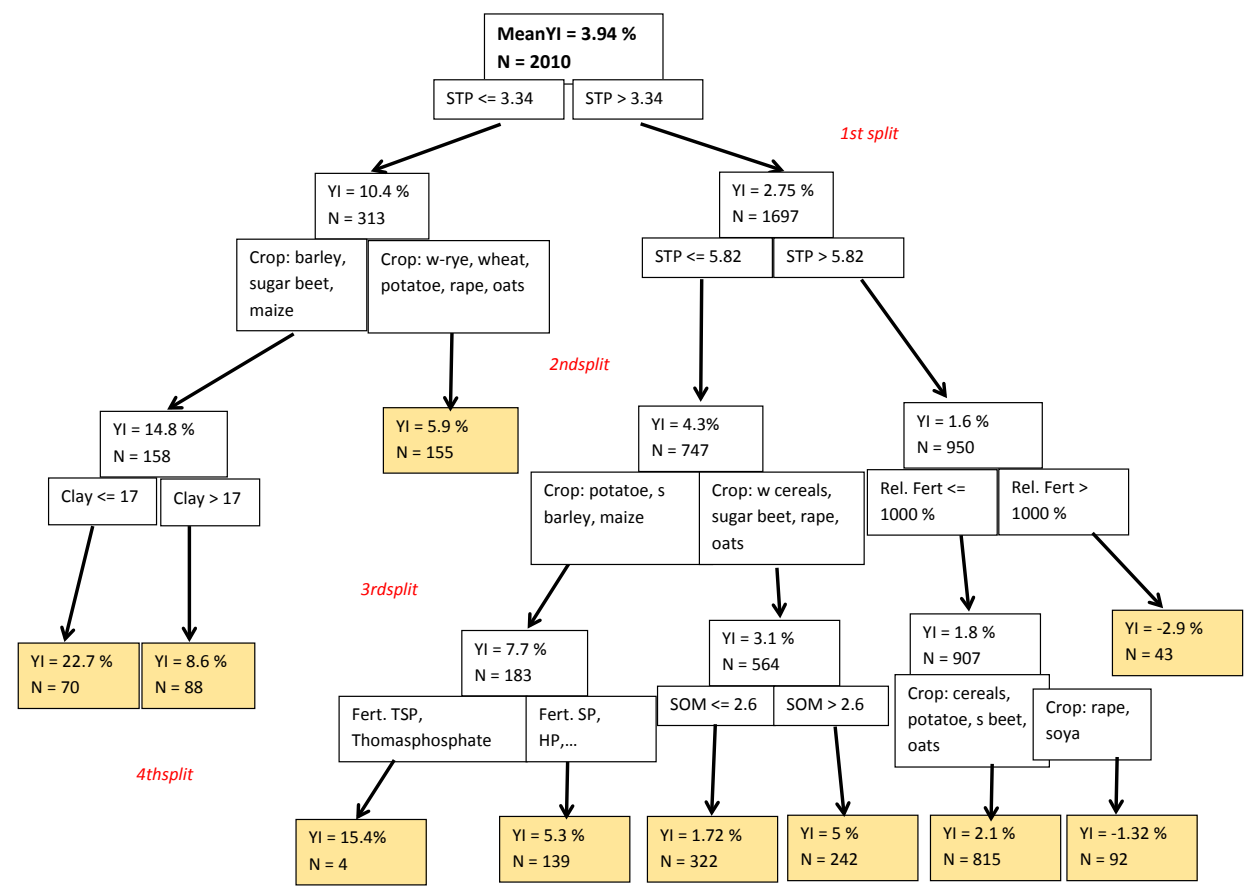

Figure 2. CART analysis of rel. yield increase. Considered independent variables are STP, pH, SOM, clay content, rel. P fertilizer amount (\%), crop type and fertilizer type; not all these independent variables appear in the graph.

This indicates that plant-available soil $\mathrm{P}$ content is the most important variable determining yield increase by P fertilization. If the STP of the control is above $3.3 \mathrm{mg} \mathrm{P} 100 \mathrm{~g}-1$ average YI is only $2.75 \%$ (compared to $10.4 \%$ ). This result supports the latest VDLUFA recommendation (VDLUFA, 2015) to reduce the lower boundary of the P content class " $C$ " to $3.0 \mathrm{mg} \mathrm{P} 100 \mathrm{~g}^{-1}$. The second split is implemented according to crop species and again STP, i.e., these independent variables explain for each of the branches the largest part of the variance in YI. The blue end segments indicate the mean YI for the combination of parameters according to the respective branch of the decision tree. This can be demonstrated exemplarily for a data set from Rottenhaus (Austria) dating from 
the year 1981 (Spiegel et al., 2001). The plant available soil P content is $4.5 \mathrm{mg} \mathrm{P}$ $100 \mathrm{~g}^{-1}$ soil, i.e., at the lower margin of P content class C (VDLUFA, 1997). Clay content is $30 \%$ and $\mathrm{pH} 5.98$.

The fertilizer application rate of $172 \mathrm{~kg} \mathrm{P} \mathrm{ha}^{-1} \mathrm{y}^{-1}$ in form of Superphosphate corresponds to $642 \%$ of $\mathrm{P}$ export by the crop (26.8 $\mathrm{kg} \mathrm{P} \mathrm{ha}^{-1}$ ). Nevertheless, the fertilizer application rate is, according to the CART analysis, not among the most important variables explaining the observed yield increase. For this dataset, the predicted YI is 5.3 \% (Fig. 2), whereas measured YI is $4.5 \%$. Similarly, multiple linear regression analysis suggests that plant available $\mathrm{P}$ content, $\mathrm{pH}$ value, and SOM content are the most significant variables, however with large differences among different fertilizer types.

\section{CONCLUSIONS}

This meta-analysis of a database of long-term field experiments of $\mathrm{P}$ fertilization covering various regions of Germany and Austria including about 2000 data sets from 30 field sites revealed that yield increase due to the effect of fresh $\mathrm{P}$ application is determined mainly by plant-available $\mathrm{P}$ in the soil, $\mathrm{pH}$ value, SOM, type of fertilizer, and crop type, whereas the exact amount of $\mathrm{P}$ fertilizer has less importance. The database will be expanded in the near future, and additional parameters will be included in the analysis, most notably soil type, precipitation, and air temperature. In a next step, the results will be utilized to refine the current $\mathrm{P}$ fertilizer recommendations.

Although only data from Germany and Austria are utilized in the present analysis, this approach can be extended to other countries worldwide, and the results gained in the analyses can be transferred to other environmental conditions and countries. This could contribute to more precise $\mathrm{P}$ fertilization recommendations, less application of $\mathrm{P}$ fertilizer, and diminished negative environmental impacts of $\mathrm{P}$ fertilization.

\section{ACKNOWLEDGEMENTS}

This work was conducted within the framework of the "InnoSoilPhos" project (BMBF BONARES program, Grant No. 031A558A). The contribution of numerous field trial operators is acknowledged: Ines Bull (MecklenburgVorpommern Research Centre for Agriculture and Fisheries), Bettina EichlerLöbermann (Department of Crop Science, University of Rostock), Wolfgang Gans (Martin Luther University Halle-Wittenberg), Johannes Heyn/Dierk Koch (Landesbetrieb Landwirtschaft Hessen), Ines Merbach (Helmholtz-Centre of Environmental Research), Markus Mokry (Agricultural Technology Center Augustenberg), Kerstin Panten (Federal Research Centre for Cultivated Plants Braunschweig), Edgar Peiter (Martin Luther University Halle-Wittenberg), Thomas Reitz (Helmholtz-Centre for Environmental Research), Martin Rex (Agricultural Research Station Kamperhof), Heide Spiegel (Austrian Agency for Health and Food Safety), Sabine von Tucher (Technical University of Munich). 


\section{REFERENCES}

Baier J., Baierová V., Bartošová Z., Ledvinková D. (2001). Yields nutrient intake and soil fertilizing in 40 years fertilizer trials. Archives of Agronomy and Soil Science, 46(3-4): 313-337.

Buczko U., Kuchenbuch R.O. (2007). Phosphorus indices as risk assessment tools in the U.S.A. and Europe-A review. J. Plant Nutr. Soil Sci., 170: 445-460.

Buczko U., van Laak M., Eichler-Löbermann B., Gans W., Merbach I., Panten K., Peiter E., Reitz T., Spiegel A., von Tucher S. (2018). Re-evaluation of the yield response by phosphorus fertilization based on meta-analyses of long-term field experiments. Ambio 2018, 47(Suppl. 1): S50-S61.

Forde B., Lorenzo H. (2001). The nutritional control of root development. Plant Soil, 232: 51-68.

Gerke J. (2015). The acquisition of phosphate by higher plants: Effect of carboxylate release by the roots. A critical review. Journal of Plant Nutrition Soil Science, 178: 351-364.

Jordan-Meille L., Rubæk G.H., Ehlert P.A.I., Genot V., Hofman G., Goulding K., Recknagel J., Provolo G., Barraclough P. (2012). An overview of fertilizer-P recommendations in Europe: soil testing, calibration and fertilizer recommendations. Soil Use and Management, 28: 419-435.

Jungk, A., Claassen N., Schulz V., Wendt J. (1993). Pflanzenverfügbarkeit der Phosphatvorräte ackerbaulich genutzter Böden (plant-availability of phosphate stocks in agriculturally used soils). Journal of Plant Nutrition Soil Science, 156: 397-406.

Kuchenbuch R.O., Buczko U. (2011). Re-visiting potassium- and phosphate-fertilizer responses in field experiments and soil-test interpretations by means of data mining. Journal of Plant Nutrition Soil Science, 174: 171-185.

Merbach I., Schulz E. (2012). Long-term fertilization effects on crop yields, soil fertility and sustainability in the Static Fertilization Experiment Bad Lauchstädt under climatic conditions 2001-2010. Archives of Agronomy and Soil Science, 59(8): 1041-1057.

Ott C., Rechberger H. (2012). The European phosphorus balance. Resources, Conservation and Recycling, 60: 159-172.

Spiegel H., Lindenthal T., Mazorek M., Ploner A., Freyer B., Köchl A. (2001). Ergebnisse von drei 40jährigen P-Dauerversuchen in Österreich: 1. Mitteilung: Auswirkungen ausgewählter P-Düngerformen und -mengen auf den Ertrag und die PCAL/DL-Gehalte im Boden (Results of three long-term P-field experiments in Austria 1st Report: Effects of different types and quantities of P-fertiliser on yields and P CAL/DL contents in soils). Die Bodenkultur, 52: 3-17.

Tóth G., Guicharnaud R.A., Tóth B., Hermann T. (2014). Phosphorus levels in croplands of the European Union with implications for P fertilizer use. European Journal of Agronomy, 55: 42-52.

VDLUFA (1997). VDLUFA Standpunkt : Phosphordüngung nach Bodenuntersuchung und Pflanzenbedarf (VDLUFA position paper : P fertilization according to soil analysis and crop requirements), Eigenverlag Darmstadt.

VDLUFA (2015). Phosphordüngung nach Bodenuntersuchung Anpassung der Richtwerte für die Gehaltsklassen ist geboten und notwendig. Positionspapier des Verbands Deutscher Landwirtschaftlicher Untersuchungs und Forschungsanstalten. (P fertilization according to soil analysis - adjustment of content classes is necessary. VDLUFA position paper) 
von Tucher S. (2013). Einfluss von Boden und P-Düngerform auf die P-Aufnahme einiger mono- und dikotyler Pflanzenarten (Influence of soil and P fertilizer type on $\mathrm{P}$ uptake of some mono- and dicotyledonous plant species). 18. Alpenländisches Expertenforum 2013: 5-8.

Williams A., Manoharan L., Rosenstock N.P., Olsson P.A., Hedlund K. (2017). Longterm agricultural fertilization alters arbuscular mycorrhizal fungal community composition and barley (Hordeum vulgare) mycorrhizal carbon and phosphorus exchange. New Phytologist, 213: 874-885.

Withers P.J.A., Sylvester-Bradley R., Jones D.L., Healey J.R., Talboys P.J. (2014). Feed the crop not the soil: rethinking phosphorus management in the food chain. Environmental Science and Technology, 48: 6523 - 6530. 